Original Research Paper

\title{
Bloodbuddy: a Tracking System for Blood Donor Using GPS
}

\section{Nur Fatini Zahidah Zakaria ${ }^{1}$, Zulhafiza Zainal Abidin', Muhammad Asyraf Abdullah Zawawi $^{2}$, Siti Nur Shuhada ${ }^{3}$}

${ }^{1}$ Program of Software Engineering, Department of Computing, Faculty of Arts, Computing, and Industry Creative. Universiti Pendidikan Sultan Idris, Malaysia.

${ }^{2}$ Program of Information Technology (Education), Department of Computing, Faculty of Arts, Computing, and Industry Creative. Universiti Pendidikan Sultan Idris, Malaysia.

${ }^{3}$ Willowglen MSC Berhad. Bandar Baru Sri Petaling. 57000 Kuala Lumpur, Malaysia.

Article History

Received:

11.07.2020

Revised:

27.08.2020

Accepted:

29.08.2020

*Corresponding Author: Nur Fatini Zahidah Zakaria Email:

nurfatinizahidah.zakaria97@

gmail.com

This is an open access article, licensed under: $\mathrm{CC}-\mathrm{BY}-\mathrm{SA}$
Abstract: Blood donation is one of the most significant contributions towards the society. Millions of people need blood transfusions each year. Some may need blood during surgery. Others depend on it after an accident or because they have a disease that requires blood components. This study is aim to develop and evaluate the impact of tracking system in the blood shortage situation which is the urgent requirement of the fresh blood and to improve the communication between the hospital and donor. This system will locate the nearest blood donor in cases of emergencies in fastest and easiest way using GPS.The findings on the views of user on the aspects of interface design, navigation and functionality of the web-based application that is developed are presented. Data analysis was done based on the questionnaire received from few users which are student from Universiti Pendidikan Sultan Idris (UPSI). The findings of this study were analysed according to the objectives and the research questions of the project.

Keywords: Blood Donation, GPS, Tracking System. 


\section{Introduction}

Currently the world depends on technology and everyone from the young to the old seem to be deeply involved. Due to the rapid development of technology, it play a significant role in the modern life of people and it important elements in today's society. One of the current technology is location tracking. A tracking system is a well-established technology in this era which is reliable technology. It detects the current geolocation of a target, which may be anything from a vehicle to an item in a manufacturing plant to a person.Using GPS enabled smartphones to collect route data is relatively new technologies, but rapidly advancing technique used in research. Smartphone GPS tracking (SGT) has been employed mainly in transportation and mobility studies [1]. This study is aim to develop and evaluate the impact of tracking system in the blood shortage situation which is the urgent requirement of the fresh blood.

Blood donation is one of the most significant contributions towards the society. Millions of people need blood transfusions each year. Some may need blood during surgery. Others depend on it after an accident or because they have a disease that requires blood components. According to World Health Organization, stated that in order to full filled the blood demand, $4.6 \%$ out of the population should come forward as a donor but only $2.25 \%$ who altruistically be as a donors [2].

Almost every hospital in Malaysia has the similar function of blood transfusion center. Although the government has this kind of facility, the government also took another extra initiative to attract more and more people to become blood donor. Therefore, the government came out with the idea of mobile blood transfusion service center. This mobile service center can be used during their blood donation campaign tournament nationwide [3]. It provides alert on donation eligibility and blood donation sites location navigation. Moreover it also provides information on the upcoming events that will take place in National Blood Center through push messages and event notification.

Lastly this study is aim to develop and evaluate the impact of tracking system in the blood shortage situation which is the urgent requirement of the fresh blood and to improve the communication between the hospital and donor. This system will locate the nearest blood donor in cases of emergencies in fastest and easiest way using GPS.

Blood donation awareness is still low, in year 2015 with only 660,000 people or just 2.25 percent of the entire Malaysian population donating blood. About 2,000 pints of blood is needed daily to treat 1,000 patient and shortage of blood is expected to occur if there is no awareness to donate blood.The National Blood Centre is calling on more Malaysians to donate blood, especially ahead of the festive season and school holidays, blood supply at hospitals nationwide would drop to below the safe limit of 3,000 blood bags a day.

According to National Blood Center director Dr Noryati Abu Amin, ensuring an adequate blood supply in health facilities is a very challenging task because they has to be prepared for unpredictable, emergency cases. At the same time, the huge blood supply cannot be keep because it has a shelf life [4].

In existing system is time consuming to provide request with the blood when in need and it just alert on donation eligibility and blood donation sites location navigation. The existing system also provides information on the upcoming events that will take place in National Blood Center through push messages and event notification. This give pries the need of such system which is available to everyone and can be used for blood management. The proposed system is a way to handle blood management and provide to hospital with blood in emergency in shortest time possible.

This system will locate the nearest blood donor in cases of emergencies and in fastest way. At the same time, the admin (user) of the system analyze the blood donor details such as type of blood will notify the blood donor. The proposed system is a way to handle blood management and provide blood in emergency in shortest time possible.

Blood is one of the most important elements of human body, it can be defined as fluid in the body that carry oxygen from lungs to the rest part of the body. We have 4 to 6 liters of blood in our adult body depend on size. This system is proposed to locate the nearest blood donor in cases of emergencies and in fastest way. This research also is solve the blood management's problem where the blood can't be keep for a long time and cause blood bank require blood anytime.

A tracking system is used for the observing of persons or objects on the move and An ideal system constantly updates the target's location, elevation, and range.Example of tracker is GPS tracking unit is a navigation device normally carried by a moving vehicle or person that uses the Global Positioning System (GPS) to track the device's movements and determine its location. 


\section{Literature Review}

In this research, there are some literature review has been conducted. The purposed of making literature review is to establish a theoretical framework for the topic or subject area. Other than that, it to provide an overview of sources such that need to be explored while researching a particular topic and to demonstrate to reader how the research fits within the larger field of study. A literature review may consist of key terms, definitions and terminology identify studies, models, case studies etc. The goal of this literature review is to explain the keywords of this research such as blood donation, location tracking, and existing blood donation system and software development models.

\subsection{Blood Donation}

Blood is essential to life, it circulates through our body and delivers essential substances like oxygen and nutrients to the body's cell. At the same time, it also transport metabolic waste products away from those same cells. There is no substitute for blood because it cannot be made or manufactured. There many reasons patients need blood such as being treated for cancer, undergoing orthopedic, cardiovascular surgeries and being treated for inherited blood disorders. This was further compounded by the increasing blood demands year over year due to an increase in medical specialties [5]. Generous blood donors are the only source of blood for patients in need of a blood transfusion. According to World Health Organization, stated that in order to full filled the blood demand, $4.6 \%$ out of the population should come forward as a donor but only $2.25 \%$ who altruistically be as a donors [2].

There are many initiatives that implemented by government such as intensive advertising, mobile blood transfusion service center, incentives to blood donor, establishment of donation suites and collaboration with other government institution for blood campaign. This initiatives is to attract the interest of public to become volunteer blood donor but blood donation awareness is still low, in year 2015 with only 660,000 people or just 2.2 percent of the entire Malaysian population donating blood last year. About 2,000 pints of blood is needed daily to treat 1,000 patient and shortage of blood is expected to occur if there is no awareness to donate blood. Moreover blood cannot be manufactured outside the body and has a limited shelf life so the supply must constantly be replenished by generous blood donors.

\subsection{Location Tracking}

A location tracking system is a well-established technology in this era which is very safe and reliable technology. It detects the current geolocation of a target, which may be anything from a vehicle to an item in a manufacturing plant to a person. A GPS navigation device built into your car or a smartphone with a GPS chip. Using GPS enabled mobile phone (smartphone) to collect route data is another relatively new but rapidly advancing technique used in research [1]. It have significantly increased the frequency and quality of available spatio- temporal data [6]. In urban settings, smartphone GPS tracking has been employed mainly in transportation and mobility studies. GPS can pinpoint a device's location with accuracy and by comparing coordinates, the statistics can be used to calculate a devices direction of movement and speed. In this case, location data can be recorded at one minute intervals, and each location is tagged with corresponding estimate of accuracy [7].

Smartphones and tablets is use on a regular basis day. One of the best features for using GPS tracking system is that it is compatible with mobile phones, and easy to use as other application on mobile phone. It has been suggested that newer consumer-oriented technologies such as smartphone and wearable activity tracker might address these challenges. Moreover, such devices are intuitively appealing since users already use them and thus may remember to use them more easily [8]

The data collection approach presented here is cost effective, accessible and user-friendly as participant use their own smart phone and do not need to carry a GPS logger or download a specific software application [1]. This significantly reduces investments cost, the potential loss of the research equipment and the need for training for participation.

However, there is limitation of using mobile phones (smartphone) such as battery life and skepticism about using personal phones for research [9].

\subsection{Existing Blood Donation System}

There are two existing system that researcher choose to compare that is MyBlood and Blood Management System.

MyBlood application is an android application that provides alert on donation eligibility and 
mobile blood donation location. This app was developed on collaboration effort between UTM and PDN. It also provides information on the upcoming events that will take place in National Blood Center through push messages and event notifications.

Next is Blood Management system is proposed to provide a management functional to the blood bank in order to handle the blood bag. The user can key in the results of blood test that has been conducted to each of the blood bag received by the blood bank. At the same time this system can generate the several type of report such as blood stock report, donor's gender report and the total of blood donation according to month and years. The system also can give the information to the donor about blood analysis test results for each time the donor made contribution.

Table 1. shows the comparison of the existing system in term of interface, location tracking function and Platform use.

Table 1. The Comparison of the Existing System in Term of Interface, Location Tracking Function and Platform Use

\begin{tabular}{|c|c|c|c|}
\hline System & MyBlood & $\begin{array}{c}\text { Blood Management } \\
\text { system }\end{array}$ & BloodBuddy \\
\hline Interface & User- friendly & User- friendly & User- friendly \\
\hline $\begin{array}{c}\text { Location } \\
\text { Tracking }\end{array}$ & $\begin{array}{c}\text { Track blood } \\
\text { donate campaign }\end{array}$ & - & $\begin{array}{c}\text { Location tracking using } \\
\text { GPS }\end{array}$ \\
\hline Platform & $\begin{array}{c}\text { Mobile } \\
\text { Application }\end{array}$ & Web Based & Web Based \\
\hline
\end{tabular}

\subsection{Software Development Models}

The software development models are the various processes or methodologies that are being selected for the development of the research depending on the research's aims and goals. There are many development life cycle models that have been developed in order to achieve different required objectives. The models specify the various stages of the process and the order in which they are carried out. The processes and templates used during the software engineering cycle have been simplified from the text, which contain more detailed descriptions.

Based on the literature review researcher did, the researcher choose prototyping as the software methodology for this research. the process of creating a system implementation from the design. There are a large number of integrated development environments (IDEs) for use in developing applications in the provided framework [10]. Along with relatively short research durations, budgets provide insight into research execution. Both factors had significant associations with the development approaches.However, more empirical work is needed; not only to examine the role of other factors such as the degree of business and technology dynamism, uncertainty and risk, but also to ascertain the optimal fit between contingent factors and methodologies to ensure positive research outcomes [11].

\section{Methodology}

The software development models are the various processes or methodologies that are being selected for the development of the research depending on the research's aims and goals. The word "model" is used to refer to any process, approach, framework, method, model, set of guidelines, or lifecycle.There are many development life cycle models that have been developed in order to achieve different required objectives. The models specify the various stages of the process and the order in which they are carried out. The researcher will choose the best software process model that is appropriate with the research.

\subsection{Research Design}

The research for the development of the BloodBuddy system was undertaken by way of qualitative and quantitative approaches in order to obtain the necessary data we needed with regards to aspects of the blood donation process. This was aid us in the development of an incentive of this system. 


\subsection{Software Development Methodology}

In choosing the development methodology of the product, there are various processes or methodologies that can be selected for the development of the researh depending on the research's aims and goals. The models specify the various stages of the process and the order in which they are carried out. The researcher choose framework on prototyping model in developing the product. Figure 1 shows a prototyping model.

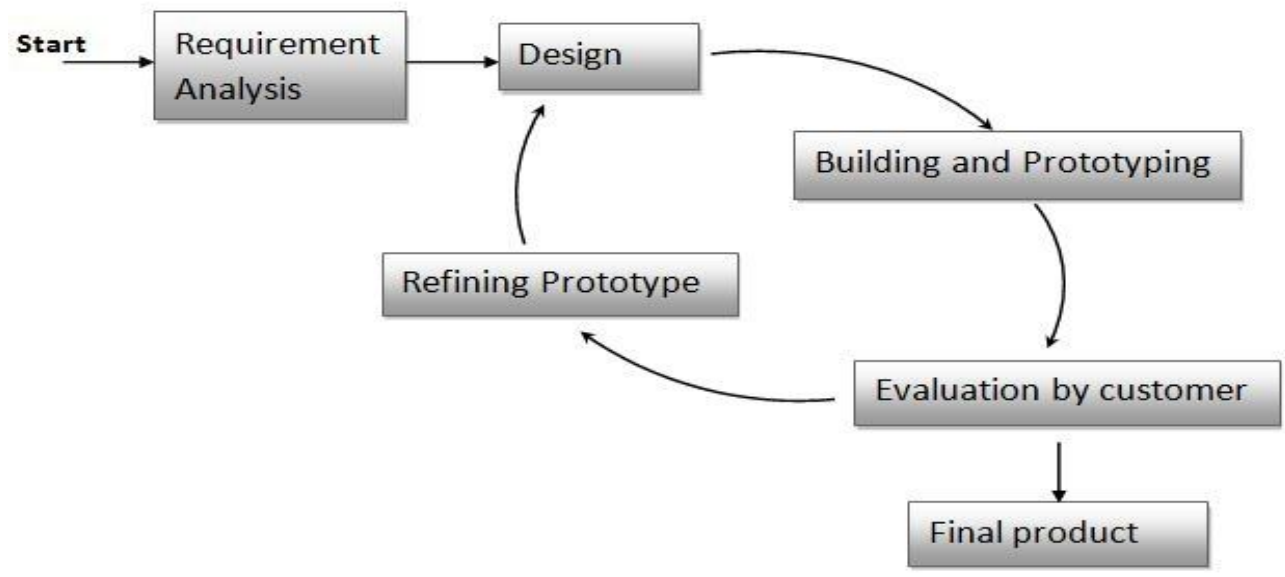

Figure 1. Prototyping Model

This model contains six phases which are requirement analysis, design, building and prototyping, evaluation by customers, refining prototype and final product. There are the major software prototyping types used widely such as rapid prototyping, evolutionary prototyping, incremental prototyping and extreme prototyping. The researcher choose extreme prototyping to develop this system. This type of prototyping consist of three sequential phases. First, a basic prototype with all the existing pages is presented in the HTML format. Then the data processing is simulated using a prototype services layer. Finally, the services are implemented and integrated to the final prototype. This process is called Extreme Prototyping used to draw attention to the second phase of the process, where a fully functional user interface is developed with very little regard to the actual services.

\subsection{Justification Methodology Selection}

The researcher choose this type of prototyping because extreme prototyping is used in the web development domain. It also because of the desired system needs to have a lot of interaction with the end users and typically, online systems, web interfaces have a very high amount of interaction with end users. Since a working model of the system is displayed, the users get a better understanding of the system being developed. It might take a while for a system to be built that allows ease of use and needs minimal training for the end user. Therefore, it can reduces time and cost as the defects can be detected much earlier and quicker user feedback is available leading to better solutions.

\subsection{Prototyping Model}

Prototyping model consist of view phases, namely requirement analysis, design, building and prototyping, evaluation by customer, refining prototype, final product.

\subsubsection{Requirement Analysis}

A prototyping model begins with requirements analysis and the requirements of the system are defined in detail. The research for development of this system is undertaken by the way of qualitative and quantitative approach in order to obtain the necessary data. The expert will be interview with regard to aspects of the blood donation process. Direct interview involved reaching out to people that is expert about blood donation process such as user from national blood center or hospital. This was in quest to find out the blood donation procedures and the existing of blood donation system. Interview question will be attach in appendix.

\subsubsection{Design}


Once the analysis is complete, the step of designing takes over, which is basically building the architecture of the project. It is not a detailed design and includes only the important aspects of the system, which gives an idea of the system to the user.This step helps remove possible flaws by setting a standard and attempting to stick to it.

\subsubsection{Building and Prototyping}

The initial Prototype is developed in this stage, where the very basic requirements are showcased and user interfaces are provided. These features may not exactly work in the same manner internally in the actual software developed. While, the workarounds are used to give the same look and feel to the customer in the prototype developed.

\subsubsection{Evaluation by Customer}

The prototype developed is then presented to the customer and the other important stakeholders in the research. The feedback is collected in an organized manner and used for further enhancements in the product under development.

\subsubsection{Refining Prototype}

The feedback and the review comments are discussed during this stage and some negotiations happen with the customer based on factors like - time and budget constraints and technical feasibility of the actual implementation. The changes accepted are again incorporated in the new Prototype developed and the cycle repeats until the customer expectations are met.

Prototypes can have horizontal or vertical dimensions. A Horizontal prototype displays the user interface for the product and gives a broader view of the entire system, without concentrating on internal functions. A Vertical prototype on the other side is a detailed elaboration of a specific function or a sub system in the product.

The purpose of both horizontal and vertical prototype is different. Horizontal prototypes are used to get more information on the user interface level and the business requirements. It can even be presented in the sales demos to get business in the market. Vertical prototypes are technical in nature and are used to get details of the exact functioning of the sub systems. For example, database requirements, interaction and data processing loads in a given sub system.

\subsubsection{Final Product}

Once the requirements are completely met, the user accepts the final prototype. The final system is evaluated thoroughly followed by the routine maintenance on regular basis for preventing large-scale failures and minimizing downtime.

\subsection{Software and Hardware Requirement}

There are few requirement in this project.

\subsubsection{Software Requirement}

Software requirement are following:
1. Notepad ++
2. Atom
3. MySQL

\subsubsection{Hardware Requirement}

Hardawer requirement are following:

1. Computer

2. RAM: $2 \mathrm{~GB}$ and above

3. CPU: Intel processor

\subsection{Analysis and Software Design}

Analysis and software design are the study carried out in the documentation of Software Requirement \& Specification (SRS), Software Design Document (SDD) and Software Testing Document (STD). Therefore, through the SRS document provided, there are several topics to be discussed to meet the requirements of the developed system. Among the topics discussed in SRS are Use Case Diagram and Entity Relationship Diagram (ERD) and these diagrams are sketched for the development of 
the BloodBuddy tracking system. This diagram is developed to facilitate the understanding of the BloodBuddy tracking system flow. Besides, this chapter also discusses the main user interface of the BloodBuddy tracking systems.

In addition, the analysis and software design are carried out to identify the appropriate programming language used for the BloodBuddy tracking systems. Therefore, the Hypertext Markup Language (HTML) and Hypertext Preprocessor (PHP)programming language has been used to construct a web-based application and a local host server which is MySQL is used to support and build database for the BloodBuddy tracking systems. Meanwhile, the Atom is chosen as a platform for writing code and construct the BloodBuddy tracking systems's interface.

Besides preparing the SRS documents, SDD and STP documents are also necessarily required. The SDD is a complete document that describes the system architecture, database and interface design as a guidance for the development of the BloodBuddy tracking systems. Meanwhile, the STD document describes the tests that have been planned and executed on the developed system. SDD will be discussed in this chapter meanwhile the STD will be included in Appendix D.

\subsubsection{Software Requirement and Specification}

This is the software requirements specification document for the development of BloodBuddy: a tracking system using GPS. The aim of this research is to develop and evaluate the impact of real-time tracking system in the blood shortage situation which is the urgent requirement of the fresh blood and to improve the communication between the hospital and donor. This system able to locate the nearest blood donor in cases of emergencies in fastest and easiest way using GPS.

The purpose of this SRS document is to specify software requirement of the BloodBuddy: a tracking system using GPS. This SRS document provides an overview of the entire SRS with purpose, scope, definitions, acronyms, abbreviations, references and overview of the SRS. The purpose of this document is to provide an explanation of the software to be built in the form of a general overview as well as detailed and comprehensive explanations. Besides, it is also intended to be a complete specification of the functionality that the system provides and specific design and implementation details will be specified in a future document. This document will be refer in the development process and as an evaluation material during the software development process. With this document, it is hoped that software development will not generate ambiguity.

This system is to ensure the admin able to locate the nearest blood donor in cases of emergencies in fastest and easiest way using GPS.

1. User - Admin(user that control the system) and registered blood donor

2. Platform - web Based system.

This document outlines three chapter which is the introduction, the general description, and specific requirements. The introduction part has been stated in page 1 . The next chapter contains the different types of users that will be or potentially be using our product. It describes the hardware requirements, functional requirements, Data Requirements, Constraints, and some use case scenarios of how the user will be interacting with this product.The last chapter contains details that discuss about the specific requirements. It describes the external and internal requirement. The functionality of the application which is included the use case diagram for user with their functionality and also the object of the whole application. It also contains the data requirements such as the interfaces the user will be working with and the information contained at each level. It also contains information about the performance requirements and the quality attributes that will be used in the release of the product.

This system will locate the nearest blood donor in cases of emergencies in fastest and easiest way using GPS. Firstly, Donor (user) will login into the system to be able for admin to track the blood donor. Next, donor (user) of the system also can update their detail in the system. Then admin(user) need to login into the system to be able to track the blood donor nearest to the blood bank and analyze the blood donor details such as type of blood, distance of the blood donor.The proposed system is a way to handle blood management and provide requester with blood in emergency In shortest time possible.

This subsection provides the operational context for the software from a user perspective. Such information may be important to the design of the various interfaces the user may have to deal with. 
This subsection of the SRS provides a general description of any other items that will limit the developer's options for designing the application. Using this application is fairly simple and intuitive. This include:

a. Hardware limitations - The product will only work with current releases of web browsers

b. Time limitation - Tight development time might effect the progress of software.

Assumptions and dependences in the system are:

1. The WiFi connection must be reliable for the system to batch transmissions successfully to the server endpoint.

2. Just registered blood donor will be track by admin.

3. Blood donor need to login into the system for their location to be track.

BloodBuddy: a tracking system using GPS is intended for the web based platform. The product will only work with current releases of web browsers .The platform provides abstractions for all network communication interfaces and thus the hardware as well.

1. Laptop

$\checkmark$ RAM 4.0 GB or above

$\checkmark$ Processor Core i5

$\checkmark$ Hard Disk 1TB

$\checkmark$ hp Model

2. Smartphone

$\checkmark$ Internet access to access the system

This system will require several software for develop this research. Below is the each software specification that been used for this research.

1. Text editor (for editing HTML, PHP, JavaScript and CSS programming language )

$\checkmark$ Atom

$\checkmark$ Notepad++

2. Server with the following:

$\checkmark$ MySQL Database

$\checkmark$ PHP server application.

3. Client side with the following:

$\checkmark$ Web browser that supports AJAX.

$\checkmark$ User system will be run using any up to date Web Browser.

This research supports all types of web browsers. We are using simple bootstrap forms for the functions created in the BloodBuddy Web-Based System. Use case diagram is shown in Figure 2.

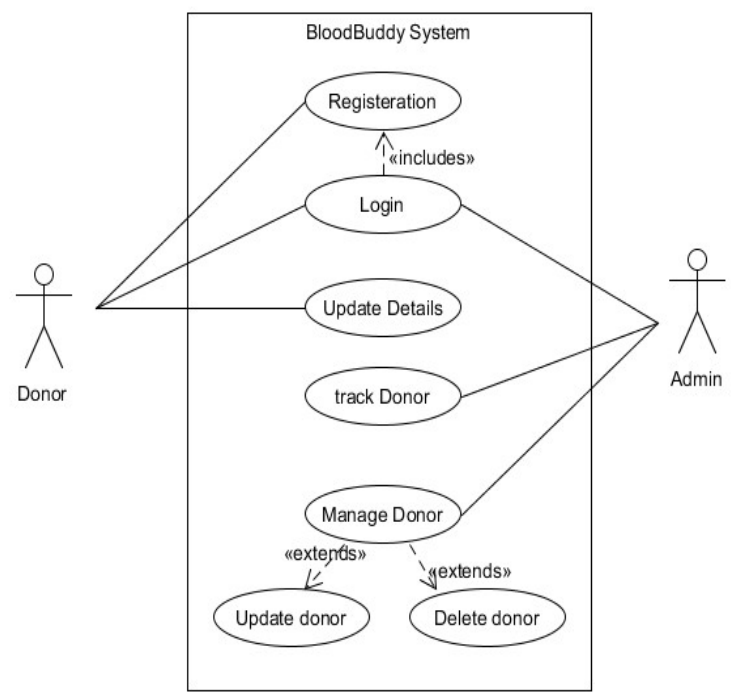

Figure 2. Use Case Diagram 
Non-functional Requirement:

1. Adaptability

The system also able to adapt to any devices that has web browser as a platform we used is web based.

2. Reliability

Once a software system is functioning, as specified. And delivered the reliability characteristic defines the capability of the system to maintain its service provision under defined conditions for defined period of time. For this software the reliability show when the network goes down for 20 seconds then comes back the system should be able to recover and continue functioning.

\section{Portability}

This characteristic refers to how well the software can adopt to changes in its environment or with its requirement. The sub characteristic of this include adaptability. This software can be use on different device such as desktop, tablet and phone.

4. Maintainability

The ability to identified and fix a fault within the software component is what the maintainability characteristic addresses. The Maintainability is also about the ease with which a program can be corrected if an error is encountered, adapted if the environment is change or enhanced if the customer want the change in the requirement.

\section{Correctness}

The system displays the right/precise data regarding the correct unique ID of the user in registration. The application displays the appropriate information as the user intended based on the correct access name and password during login phase.

\section{Flexibility}

The user can login into the web system using their own login username and password.Each of them has their own username registered through the application.

\subsubsection{Software Design Document}

This is the software design document for the development of BloodBuddy: a tracking system using GPS. The aim of this research is to develop and evaluate the impact of real-time tracking system in the blood shortage situation which is the urgent requirement of the fresh blood and to improve the communication between the hospital and donor. This system able to locate the nearest blood donor in cases of emergencies in fastest and easiest way using GPS.

This is the software requirements specification document for the BloodBuddy: a tracking system using GPS. This document describes the conceptual design of BloodBuddy: a tracking system according to the document guidelines presented in the IEEE 1016-1998 Recommended Practice for Software Design Descriptions (SDD). The SDD shows how the software system will be structured to satisfy the requirements identified in the software requirements specification. It is a translation of requirements into a description of the software structure, software components, interfaces and data necessary for the implementation phase. In essence, the SDD becomes a detailed blueprint for the implementation activity. In a complete SDD, each requirement must be traceable to one or more design entities. BloodBuddy is the system that will be used by registered blood donor and blood bank.

This document is the description of the design of the system Based Continuous On boarding Framework.Software development is a process that has deep background consisting of various phases. Even though, there are different methodologies used in software development, it has never been a straightforward process. Developers should always be highly motivated and continuously focused on the research. Otherwise, they can easily be disoriented during the development activities. All developers including juniors should always keep the pace of the process. The main goal of this research is to ensure the admin able to locate the nearest blood donor in cases of emergencies in fastest and easiest way using GPS. 
Software architecture is the high level structure used for creating software systems and is actually a step-by-step blueprint of the entire software that is to be built. The purpose of the software and its specific functionality are defined by the software's architectural style and pattern used.

The software architecture researcher choose is MVC Architecture. The rationale of choosing this architecture is because MVC architecture helps us to control the complexity of application by dividing it into three components i.e. model, view and controller.Separation of concern makes it easy for us to test our application as relation among different components of system is clearer and coherent. MVC architecture is shown in Figure 3.

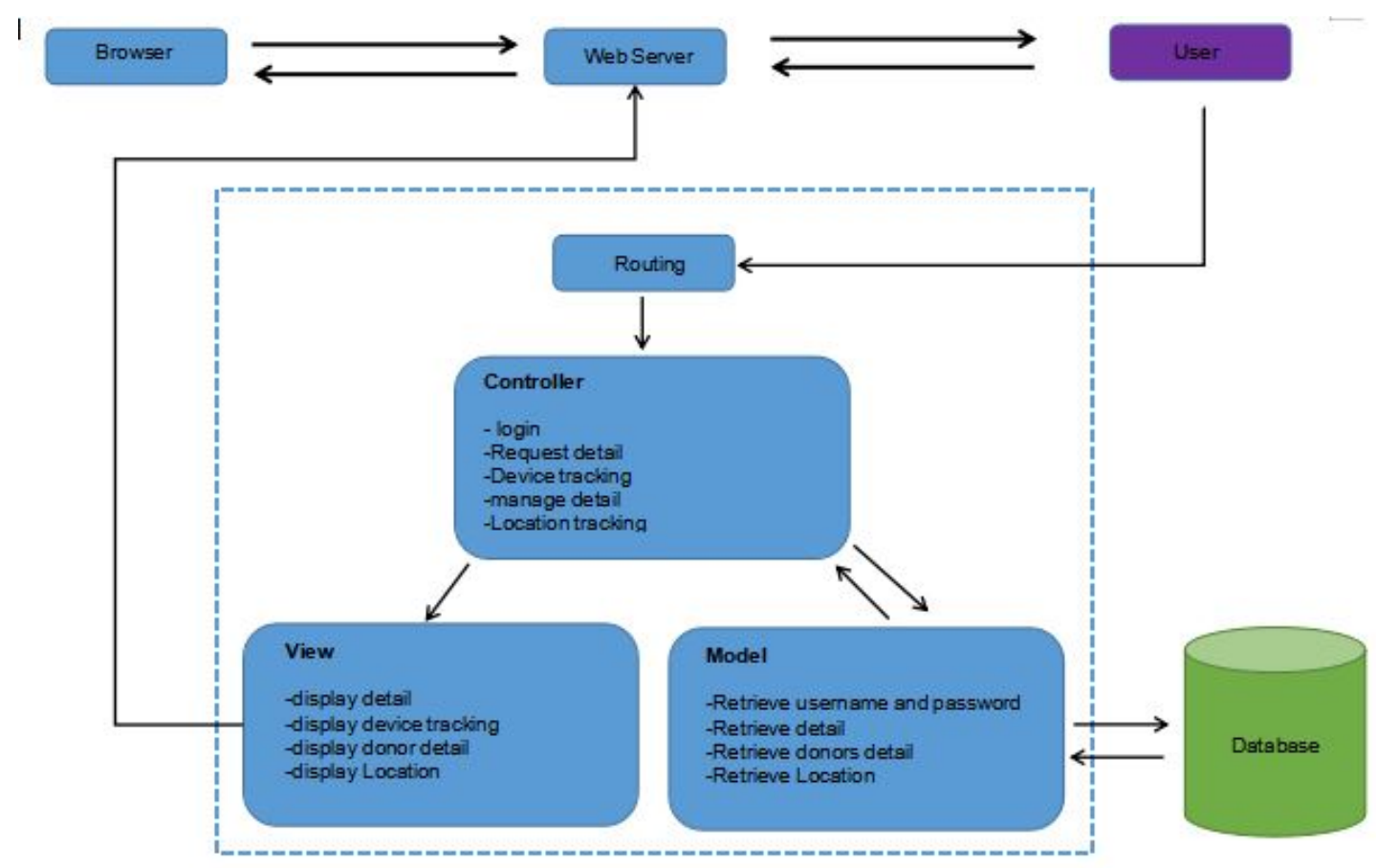

Figure 3. MVC Architecture

\subsubsection{Design Package Diagram}

Data Dictionary of donors shown in Table 2, Indexes is shown in Table 3, while gps_track is shown in Table 4.

Table 2. Data Dictionary of Donor

\begin{tabular}{|l|l|l|l|l|l|l|}
\hline \multicolumn{1}{|c|}{ Column } & \multicolumn{1}{c|}{ Type } & Null & Default & Links to & Comments & MIME \\
\hline donor_id (Primary) & $\operatorname{int}(11)$ & No & & & & \\
\hline userID & $\operatorname{int}(11)$ & No & & users -> userID & & \\
\hline IC_No & varchar(12) & No & & & & \\
\hline name & $\operatorname{varchar(255)}$ & No & & & & \\
\hline age & int(11) & No & & & & \\
\hline contact & bigint(11) & No & & & & \\
\hline address & varchar(255) & No & & & & \\
\hline TypeOfBlood & varchar(3) & No & & & & \\
\hline email & $\operatorname{varchar(255)}$ & No & & & & \\
\hline
\end{tabular}


Table 3. Indexes

\begin{tabular}{|l|c|l|l|l|l|l|l|l|}
\hline Keyname & Type & Unique & Packed & Column & Cardinality & Collation & Null & Comment \\
\hline PRIMARY & BTREE & Yes & No & donor_id & 6 & A & No & \\
\hline userID & BTREE & Yes & No & userID & 6 & A & No & \\
\hline donor_id & BTREE & Yes & No & donor_id & 6 & A & No & \\
\hline
\end{tabular}

Table 4. GPS_Track

\begin{tabular}{|l|l|l|l|l|l|l|}
\hline \multicolumn{1}{|c|}{ Column } & \multicolumn{1}{|c|}{ Type } & Null & Default & Links to & Comments & MIME \\
\hline trackID (Primary) & $\operatorname{int}(11)$ & No & & & & \\
\hline userID & $\operatorname{int}(11)$ & No & & users -> userID & & \\
\hline track_time & datetime & No & CURRENT_TIMESTAMP & & & \\
\hline track_lng & decimal(11,7) & No & & & & \\
\hline track_lat & decimal(11,7) & No & & & & \\
\hline
\end{tabular}

Indexes is shown in Table 5, Users is shown in table 6.

Table 5. Indexes

\begin{tabular}{|l|l|l|l|l|l|l|l|l|}
\hline Keyname & Type & Unique & Packed & Column & Cardinality & Collation & Null & Comment \\
\hline PRIMARY & BTREE & Yes & No & trackID & 23 & A & No & \\
\hline track_time & BTREE & No & No & track_time & 23 & A & No & \\
\hline gps_track & BTREE & No & No & userID & 23 & A & No & \\
\hline
\end{tabular}

Table 6. User

\begin{tabular}{|l|l|l|l|l|l|l|}
\hline \multicolumn{1}{|c|}{ Column } & \multicolumn{1}{c|}{ Type } & Null & Default & Links to & Comments & MIME \\
\hline userID (Primary) & $\operatorname{int}(11)$ & No & & & & \\
\hline role & $\operatorname{varchar}(15)$ & No & Donor & & & \\
\hline name & $\operatorname{varchar}(255)$ & No & & & & \\
\hline username & $\operatorname{varchar}(10)$ & No & & & & \\
\hline password & $\operatorname{varchar}(16)$ & No & & & & \\
\hline contact & bigint(11) & No & & & & \\
\hline verified & $\operatorname{tinyint(1)}$ & No & 0 & & & \\
\hline deleted & tinyint(4) & No & 0 & & & \\
\hline
\end{tabular}

Indexes is shown in Table 7.

Table 7. Indexes

\begin{tabular}{|l|l|l|l|l|l|l|l|l|}
\hline Keyname & Type & Unique & Packed & Column & Cardinality & Collation & Null & Comment \\
\hline PRIMARY & BTREE & Yes & No & userID & 7 & A & No & \\
\hline username & BTREE & Yes & No & username & 7 & A & No & \\
\hline userID & BTREE & Yes & No & userID & 7 & A & No & \\
\hline
\end{tabular}


Activity Diagram is shown in Figure 4.

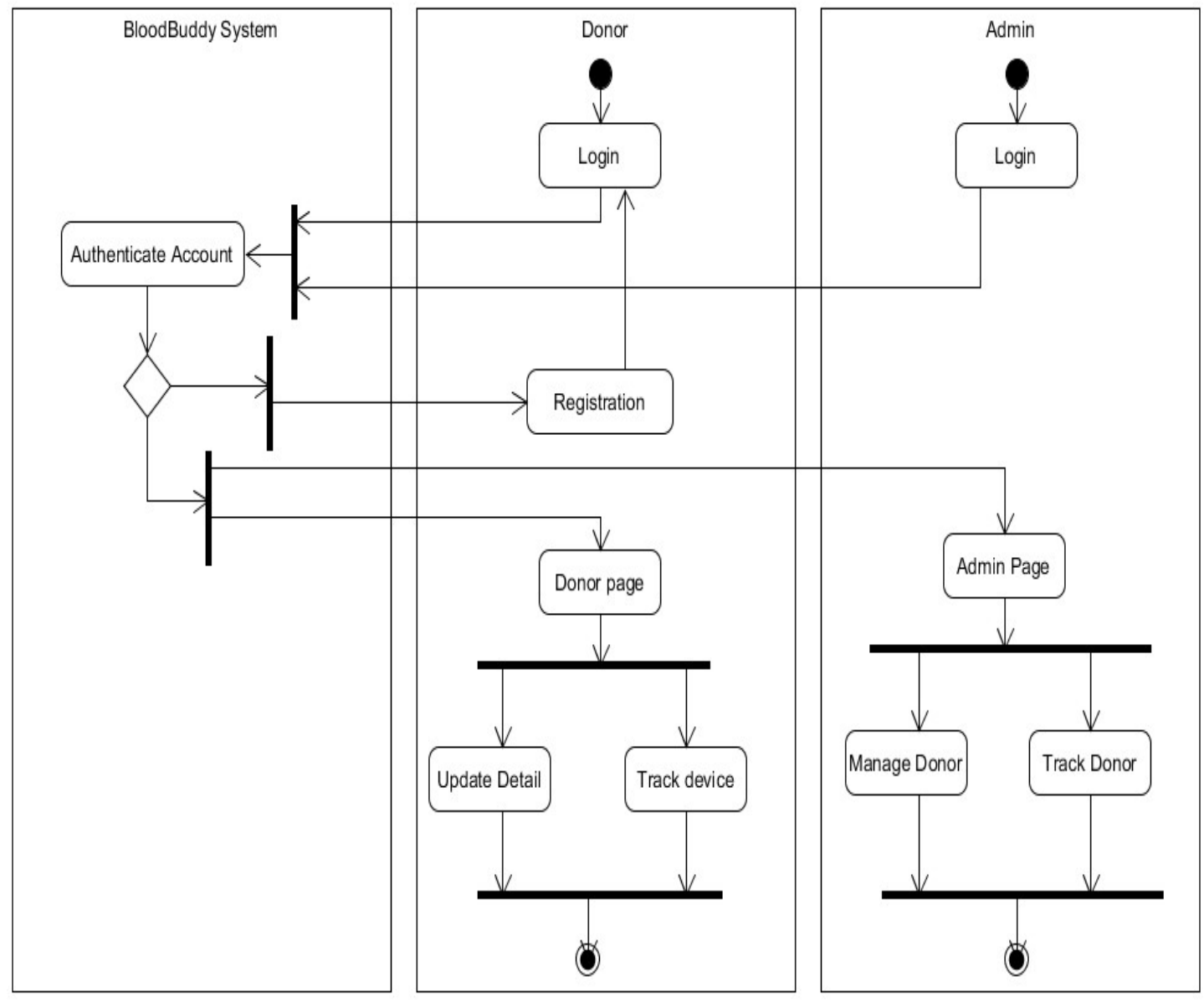

Figure 4. Activity Diagram

\subsubsection{User Interface Design}

The primary design constraint is the web based platform. Creating a user interface which is both effective and easily navigable will pose a difficult challenge. Login page Interface is shown in Figure 5.

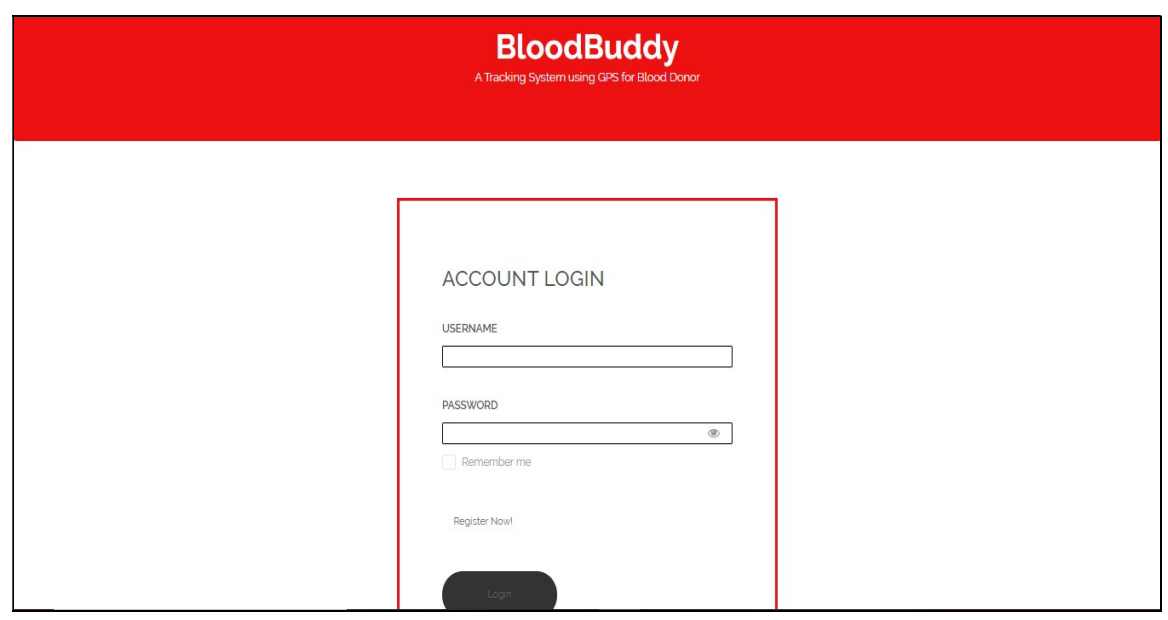

Figure 5. Main interface 
Donor track interface is shown in Figure 6.

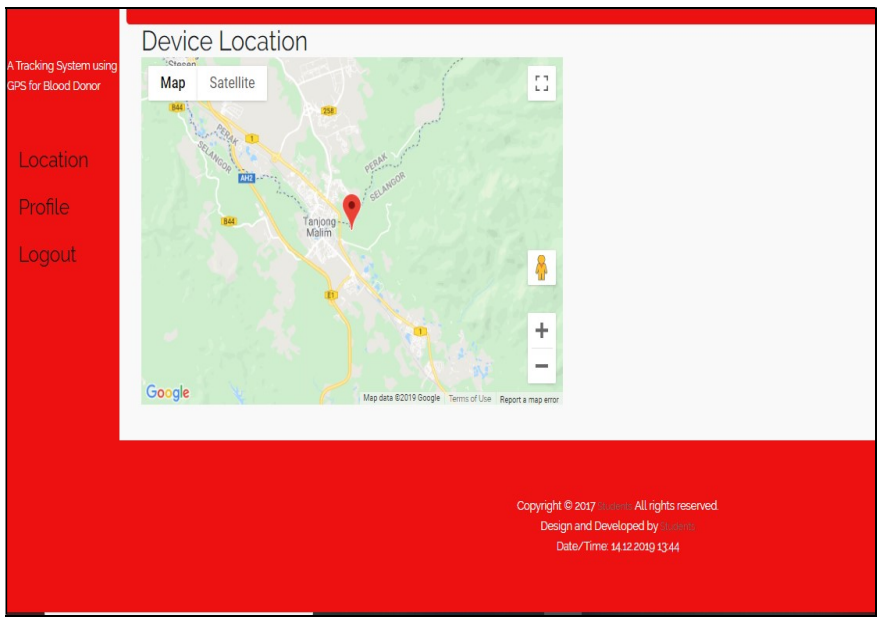

Figure 6. Create Donor Track Page

Create donor detail page Interface is shown in Figure 7.

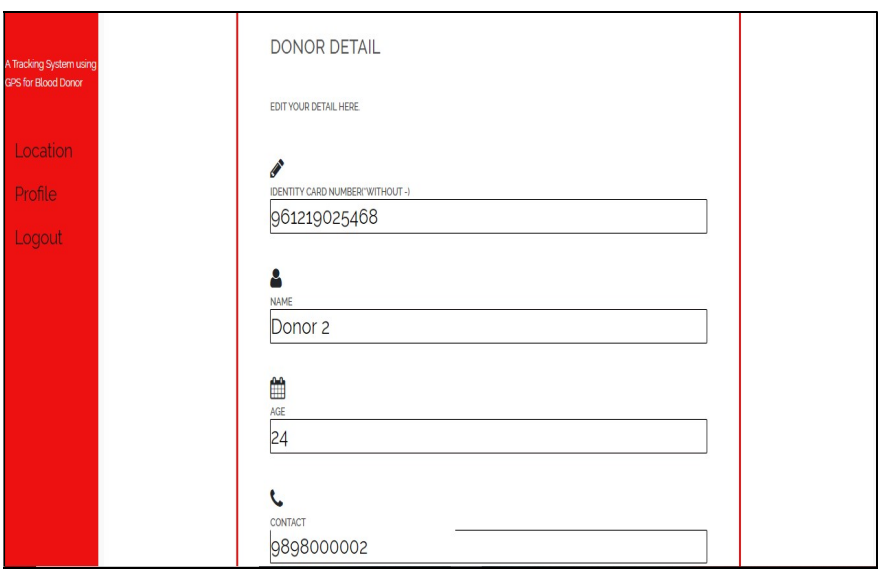

Figure 7. Control Donor Detail Interface

Create donor location page is shown in Figure 8.

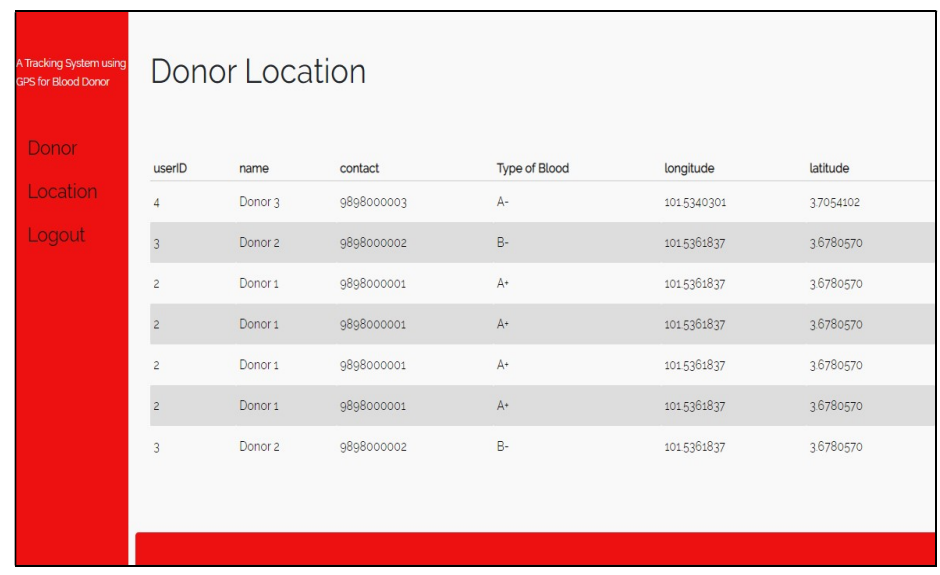

Figure 8. Control Donor Detail Interface 
System analysis is important because it is provide an avenue for solutions in the system through the various tasks involved in doing the analysis. With this various task it helps to minimize errors which reduce future IT requirements for fixing problems. While system design focuses on how to accomplish the objective of the system. It is involves identifying system components and specifying requirements for the components needed to satisfy system-level requirements.

\section{Result and Disscusion}

The findings on the views of user on the aspects of interface design, navigation and functionality of the web-based application that is developed are presented.

Data analysis was done based on the questionnaire received from few users which are student from Universiti Pendidikan Sultan Idris. The findings of this study were analysed according to the objectives and the research questions of the project.

The result of the analysis is used to develop better applications and have received encouraging response.

\subsection{Research Finding}

This section will discuss about method and instrument used for research finding.

\subsubsection{Instrument}

There are generally two types of data that can be collected namely, qualitative and quantitative data. For this study, quantitative data that was collected from the respondents are used. The evaluation was participated by user respondents whose are Student from Universiti Pendidikan Sultan Idris. The quantitative data was collected through the use of questionnaire forms which used a Likert scale with the total of 10 questions. There are two sections of the questionnaire which are respondent's information, and functionality. Respondent's information section has two questions while functionality section consist of eight question.

\subsubsection{Data Analysis}

This section will discuss about the data analysis. Analysis of respondent is shown in Figure 9.

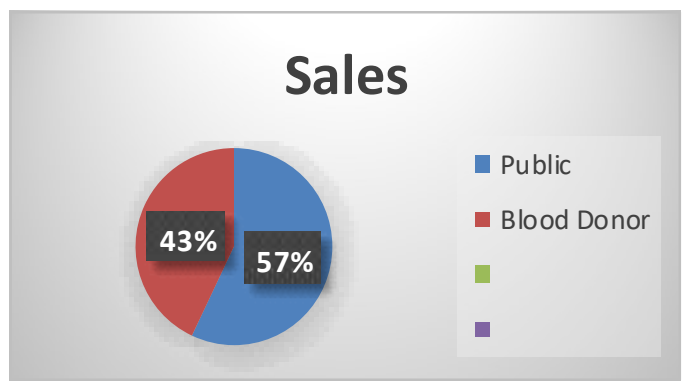

Figure 9. Pie Chart of Analysis of Respondent

The first question in respondent section is the categories of the respondent. There two categories of user that is public and blood donor, most of the user is public. The second question is about the existing product, all the respondent answer that none of them have used any application or system for blood donation.

\subsubsection{Analysis of Functionality}

This section consist of eight question that is divided to several categories that is functionality navigation and user interface. The response of the question of "the login for the system is work properly?" shown in Figure 10.

The response of the question "The button is work properly?" is shown in Figure 11. While the response of the queston "The BloodBuddy system works properly without encounter any problem?" is shown in Figure 12. 


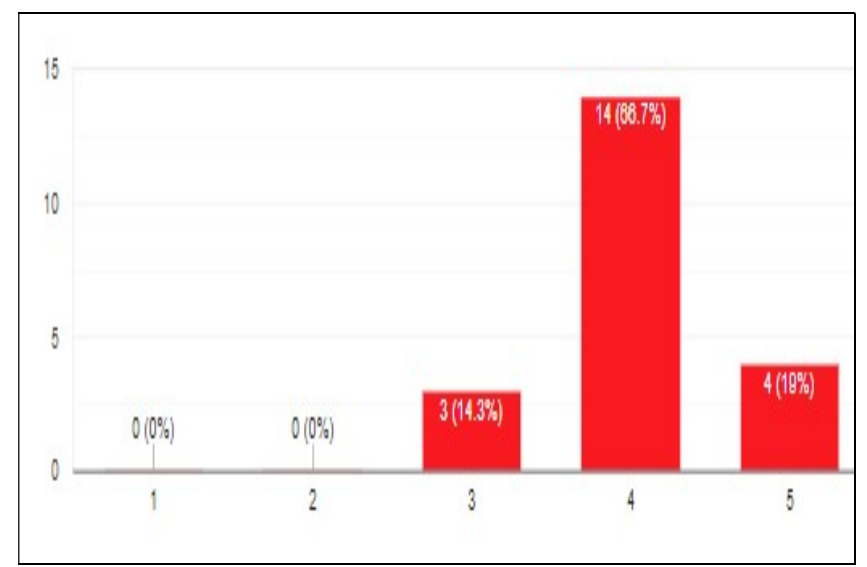

Figure 10. The Response of the Question of

"The Login for the System is Work Properly?"

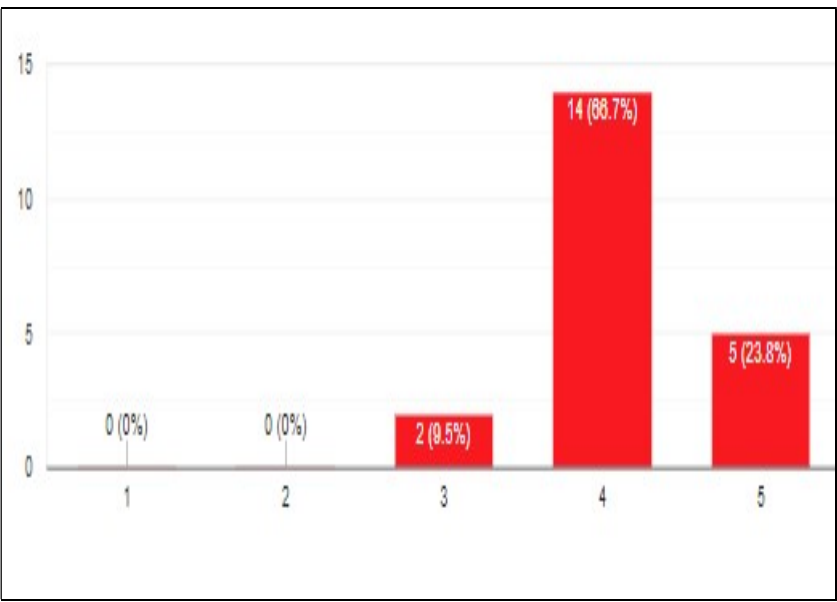

Figure 11. The Response of the Question "The Button is Work Properly?”

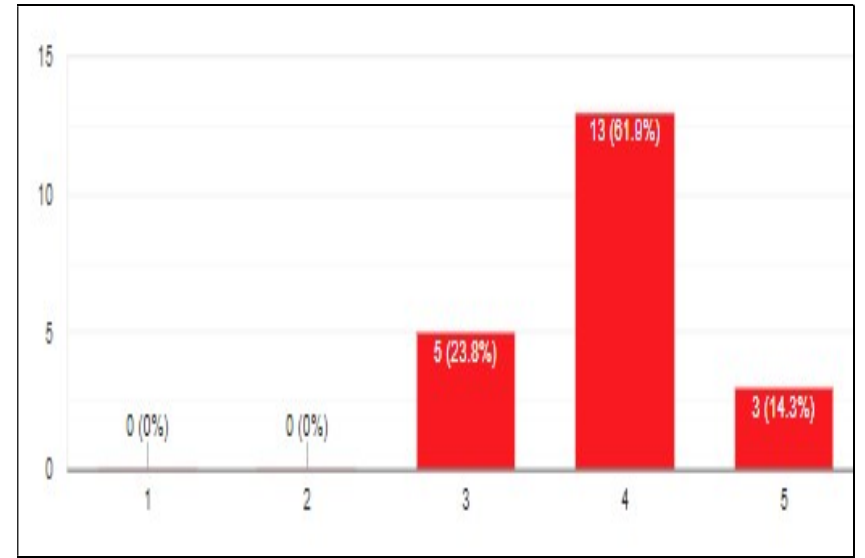

Figure 12. The Response of the Question of

"The Bloodbuddy System Works Properly without Encounter any Problem?" 
The response of question "Do you able to understand the flow of the system?" is shown in Figure 13.

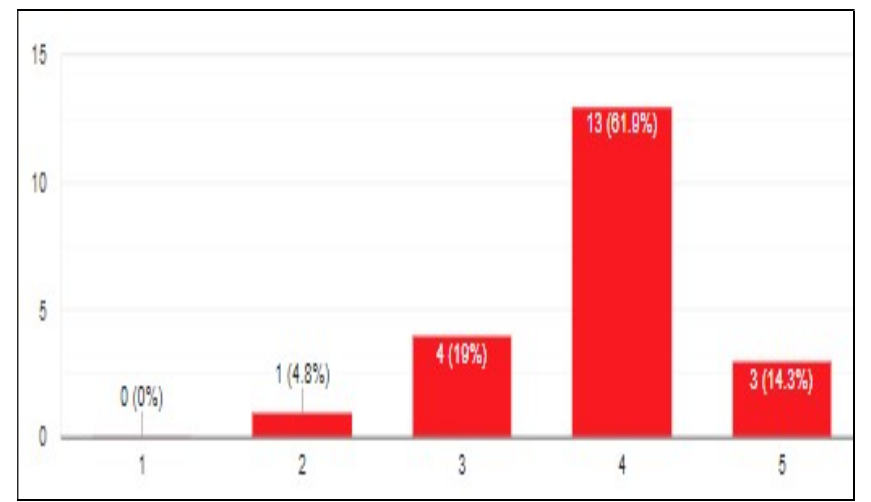

Figure 13. The Response of the Question of

"Do You Able to Understand The Flow of the System?"

The response of the question "How do you rate this system in terms of performance?" is shown in Figure 14.

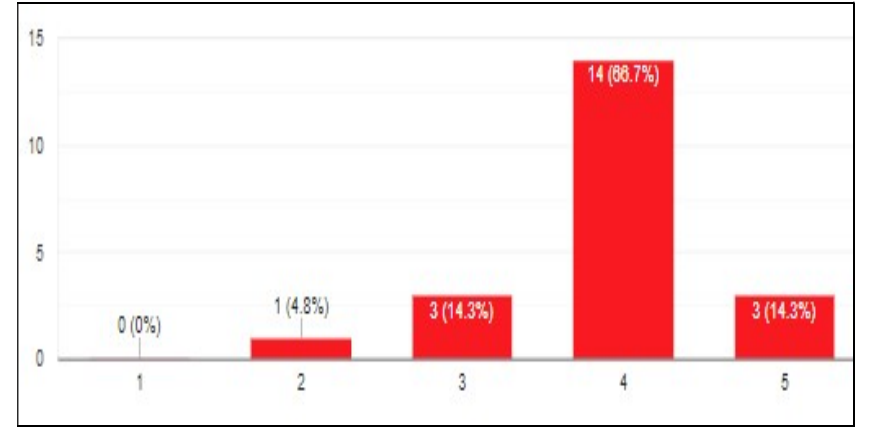

Figure 14. The Response of the Question of

"How Do You Rate this System in Terms of Performance?"

The response of the question "Is this system is easy to use?" shown in Figure 15.

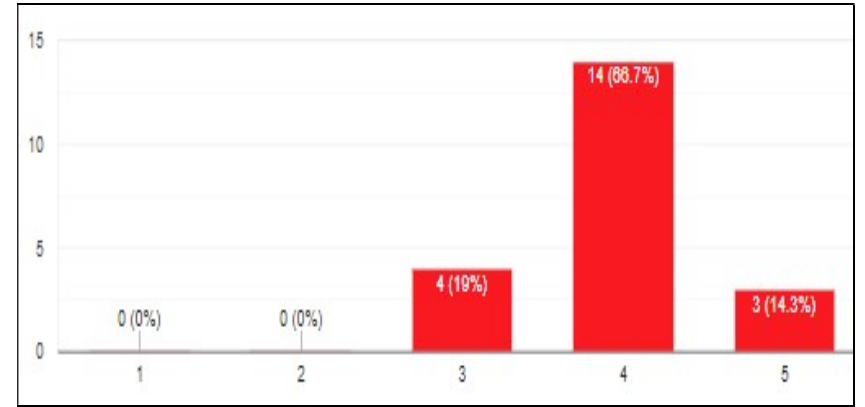

Figure 15. The Response of the Question "Is this System is Easy to Use?"

The response of the question "Overall, do you satisfy with this system?" is is shown in Figure 16. 


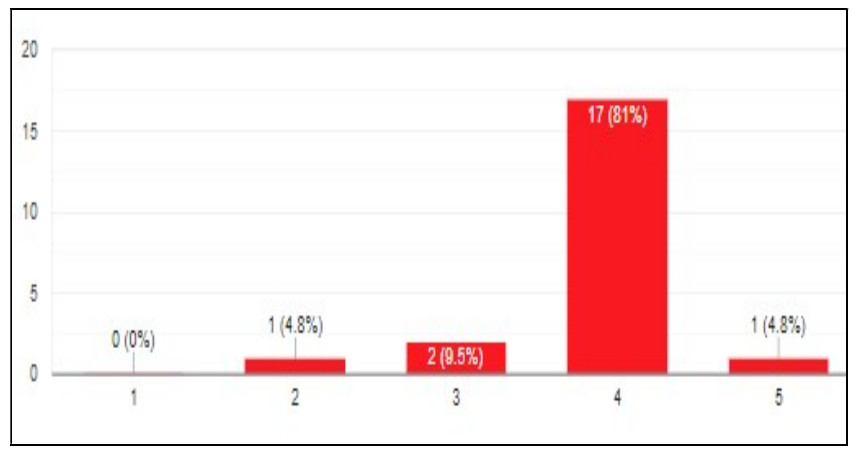

Figure 14. The Response of the Question "Overall, Do You Satisfy with this System

There is no response for the last question "Do you have any suggestion for this system?"

\section{Conclusion}

Based on the figure obtained from the respondent (Analysis of Functionality), a positive feedback has been received after the used of this system. Most of the respondent said that the System is Work Properly and can be used in real life situation.

\section{References}

[1] S. Korpilo, T. Virtanen, and S. Lehvävirta, "Smartphone GPS Tracking-Inexpensive and Efficient Data Collection on Recreational Movement," Landscape and Urban Planning, vol. $157,2017$.

[2] L. M Ling, T. S. Hui, and G. S. Ling, "Determinants of Blood Donation Status in Malaysia: Profiling the Non-Donors, Occasional Donors and Regular Donors," Kajian Malaysia, vol. 36, no. 1, pp. 43-62, 2018.

[3] Ministry of Health. Derma darah," 2018. [Online]. Available: http://www.myhealth.gov.my/derma-darah/ (2012). [Accessed: June, 25. 2018].

[4] V. Brown, "What You Can Do to Save Lives: Give Us Your Blood! The Star Retrieved," July 2017. [Online]. Available: http://www.thestar.com.my/news/nation/2017/01/10/what-you-cando-to-save-lives-give-us-your-blood/. [Accessed: June, 25. 2018].

[5] K. W. Seong, "Overcoming Blood Supply Challenges in Multi-Ethnic Donor and Patient Populations: The Malaysia Experience," ISBT Science Series, vol.12, no.1. pp. 4-10, 2016.

[6] A. Ladle, P. Galpern, and P. Doyle, "Measuring the Use of Green Space with Urban Resource Selection Functions: An Application Using Smartphone GPS Locations," Landscape and Urban Planning, vol. 179, pp. 107-115, 2018.

[7] P. Galpern, A. Ladle, and F. A. Uribe, "Assessing Urban Connectivity Using Volunteered Mobile Phone GPS Locations," Applied Geography, vol. 93, pp. 37-46, 2018.

[8] J. Hardy, T. C. Veinot, and Yan, "User Acceptance of Location-Tracking Technologies in Health Research: Implications for Study Design and Data Quality." Journal of Biomedical Informatics, vol. 79, pp. 7-19, 2018.

[9] L. Stamberger, and C. J. Riper, "A GPS Tracking Study of Recreationists in an Alaskan Protected Area." Applied Geography, vol. 93, pp. 92-102, 2018.

[10] J. Gray, T. M Banhazi, and A. A Kist, "Wireless Data Management System for Environmental Monitoring in Livestock Buildings." Information Processing in Agriculture, vol. 4. No.1, pp. 117, 2017.

[11] L. R Vijayasarathy, and C. W. Butler, "Choice of Software Development Methodologies: Do Organizational, Project, and Team Characteristics Matter?" IEEE Software, vol. 33, no. 5, pp. 86-94, 2016. 